\title{
O IMIGRANTE ÁRABE uma etnografia das famílias
}

\author{
Janie Kiszewski Pacheco * \\ Lenora Silveira Pereira*
}

"A terra, o trigo, o pão, a mesa, a família (a terra); existe neste
ciclo, dizia o pai nos seus sermões, amor, trabalho, tempo."

(Raduan Nassar, Lavoura Arcaica)

1 ntre as últimas três décadas do século XIX até meados dos anos 40 do século XX teriam entrado mais de cem mil imigrantes "turcos" no Brasil. Esses "turcos", na quase totalidade, eram imigrantes sírio-libaneses, pois até 1892 todos os indivíduos oriundos das regiões do império turco-otomano foram classificados indistintamente como "turcos" e posteriormente passaram a ser designados como "árabes"1.

Nossa intenção inicial não é tratar do tema da imigração árabe, mas contextualizá-la histórica e sociologicamente a fim de compreendermos o processo de integração deste imigrante à realidade nacional para, a seguir, considerarmos a "família árabe" em três obras de ficção: Lavoura Arcaica, Dois Irmãos e Nur na Escuridão, de Raduan Nassar, Milton Hatoum e Salim Miguel, respectivamente. Ao contrário de outros grupos de imigrantes, para Truzzi, a imigração dos sírio-libaneses foi "espontânea e individual" (Veja 04/10/ 2000:125). Tal argumento é corroborado pelo estudo de Safady ao afirmar que "não houve, no sentido próprio da expressão, imigração árabe $e^{2}$ para o
Brasil" (1994:36). Segundo ele, a imigração de japoneses, italianos e alemães se deu em decorrência de um entendimento anterior entre o governo brasileiro e os governos de onde provinham os imigrantes. Muitos vieram para substituir a mão-de-obra escrava nas fazendas, especialmente após a abolição da escravatura em 1888. Ao chegarem no Brasil, esses imigrantes receberam moradia, trabalho e até um salário antecipado. No entanto, como assinala Safady, "isso não aconteceu no caso dos árabes, que tiveram de buscar seus próprios meios de sobrevivência" (1994:37).

A trajetória de grande parte dos imigrantes árabes segue a trilha mascate, dono de loja de varejo e/ou atacadista e depois a indústria. Em busca de progresso, espalharam-se pelas diversas regiões do país onde o comércio regular não alcançara. A história da dispersão árabe pelo Brasil coincide com etapas da história recente do país. Ao colocarem suas quinquilharias na maleta e sair, de bicicleta ou no lombo do burro, de charrete ou de barco, esses imigrantes vão fincando suas raízes nos recantos mais remotos: seja durante o ciclo da borracha na região amazônica, ou do café, nas fazendas em São Paulo e no Rio de Janeiro, para lá se dirigiram os mascates a fim de vender mercadorias.

Os primeiros imigrantes síriolibaneses queriam fazer fortuna e voltar para a terra natal. No entanto, acabaram por permanecer no país, trabalharam e investiram na educação dos filhos. Hoje, os descendentes desses imigrantes marcam presença em vários setores da vida nacional. Truzzi ressalta o grande número de profissionais liberais que depois de formados em carreiras universitárias de prestígio, como direito, engenharia, medicina, se tornaram políticos (Veja, 04/10/2000:124). E, nessa escala de preferência, afirma Pereira, entre os árabes, tal como ocorre com o imigrante japonês, "as carreiras humanísticas foram negligenciadas $e$ subalternizadas" (2000:20). Portanto, não foi de imediato que os membros dessas correntes migratórias geraram obras literárias sobre seu próprio grupo étnico ${ }^{3}$ que resultassem em visibilidade do imigrante árabe na literatura brasileira. Até porque esse é um processo que aconteceu por etapas, uma vez que as primeiras gerações tinham que se preocupar em garantir a sobrevivência e o aprendizado da língua. 
Por outro lado, no Brasil dos anos 40 aos 60, o tema da imigração aparece pouco em nossa literatura, já que são épocas de nacionalismos exacerbados, às vezes beirando à xenofobia. Com o fim do regime militar e com a redemocratização do país, novas vozes, perspectivas e textos se fazem ouvir na literatura brasileira. Não é de admirar, portanto, que nos últimos anos tenham surgido muitas obras literárias, inclusive filmes, tendo como tema a imigração. No que tange a esta temática (não apenas árabe, mas também italiana e judaica, por exemplo) muitos escritores descendentes de imigrantes se tornaram conhecidos e elaboraram suas obras ficcionais valendo-se muitas vezes das situações reais enfrentadas por aqueles que aqui primeiro chegaram (a dificuldade de inserção social no novo país, o aprendizado da língua, as tensões geradas no âmbito familiar por conta desta nova situação, a manutenção dos laços de parentesco com aqueles que ficaram no país de origem, etc.).

Pensando que a literatura é uma expressão, um meio privilegiado pelo qual a sociedade pode se manifestar", como nos mostra DaMatta (1993:49), buscamos nele inspiração para "tomar a obra literária como etnografia" (1993:47), ou seja, como referência "empírica", para, assim, propormos uma reflexão teórica que privilegie a "família árabe" mediante os aspectos destacados pelos três autores citados.

Convém destacar inicialmente que a discussão antropológica do tema demanda algumas considerações de ordem teórica. Apesar do emprego corrente, em sociologia e antropologia, o conceito de família não é um conceito logicamente "claro". Os estudos antropológicos em sociedades tradicionais demonstram que o casamento, a partir do qual a família tem origem, é motivado por grupos interessados e o que une estes grupos, estando, portanto, antes e acima dos indivíduos. Sendo assim, é a família e o parentesco por meio de alianças que permitem integrar o indivíduo à sociedade $^{4}$. Cabe frisar que familia aqui está sendo considerada a partir das formulações de Lévi-Strauss para quem esta é "uma união mais ou menos duradoura, socialmente aprovada, entre um homem e uma mulher e seus filhos (...)" (1982:357), que tem sua origem no casamento, e que seus "membros estão unidos por laços legais, direitos e obrigações econômicas, religiosas ou de outra espécie, [além de] um conjunto bem definido de direitos e proibições sexuais, e uma quantidade variada e diversificada de sentimentos psicológicos, tais como amor, afeto, respeito, reverência etc." (1982:361).

Se, de um lado, na análise das três narrativas literárias, consideramos ser possível identificar que a existência desses laços familiares é conduzida entre elementos do próprio grupo étnico ou da parentela, por outro, percebemos que nessas relações são criados valores que recriam e identificam o que seja "família árabe". Ao estudar palestinos no sul do Brasil, Jardim afirma que os estudos recentes sobre família têm enfatizado sua importância no processo de construção da subjetividade e socialização do sujeito, uma vez que esta, como "instância de socialização", envolveria "não só uma rede de relações, uma parentela, mas também um modelo ideológico que aponta como deveriam acontecer alguns eventos relacionados ao ciclo de vida e à unidade doméstica. (...) são modelos que indicam quem são os incluídos $e$ excluídos dele". (2001:266)

\section{A OBRA LITERÁRIA COMO ETNOGRAFIA}

\section{Em Lavoura Arcaica}

Novela narrada em primeira pessoa por André, "o filho desgovernado", "o torto" da família imigrante árabe, que acaba por mostrar o avesso desta. A narrativa é composta de dois momentos distintos: a partida e o retorno de André ao lar. Na primeira parte são revelados os motivos de sua partida a Pedro, irmão incumbido de trazê-lo de volta. $\mathrm{Na}$ segunda, o desfecho trágico durante a festa em homenagem ao retorno de André, envolvendo sua irmã, Ana, e o pai.

A narrativa mescla poesia e prosa, parábolas, e aos poucos ficamos sabendo da devotada e incestuosa afeição do protagonista pela irmã Ana, do afeto intenso por parte da mãe e sua insubmissão à autoridade e à disciplina de vida imposta pelo pai.

\section{Em Dois Irmãos}

Romance narrado por um homem que busca descobrir a identidade de seu pai entre os homens da casa onde cresceu, em meio a pedaços de outras histórias de outras pessoas. A história tem como foco central a vida conflituosa de dois irmãos gêmeos ${ }^{5}$ - Yaqub e Omar - e suas relações com a mãe, Zana; o pai, Halim; e a irmã, Rânia. Moram na mesma casa Domingas, agregada da família, e seu filho, Nael, narrador da história, cuja infância é moldada pela condição de ser filho da agregada/ empregada. A ação do romance se passa em Manaus, no Amazonas, e inicia nas primeiras décadas do século XX. Aqueles que articulam essa trama são a família de imigrantes libaneses e suas relações com patrícios e os brasileiros.

Nael, o narrador, nos mostra Halim, o chefe da família imigrante, e os abismos familiares gerados mediante a desmedida dedicação da esposa Zana ao filho Caçula, Omar; o trauma de Yaqub, o outro filho que, aos 13 anos, foi mandado ao sul do Líbano para casa de parentes, onde ficou por cinco anos, numa infrutífera tentativa de apaziguamento dos ânimos com o Caçula; e o fascínio de Rânia pelos irmãos. Sobre Domingas, sua mãe, uma índia, o que o narrador nos diz que é que esta é mulher que não faz escolhas.

Os conflitos são alimentados pela 
rede de interditos no interior da família. Somente quando se passam mais de trinta anos, quando quase todos já estão mortos, é que o narrador parece motivado a olhar para eles e contar sua história, tentando, mediante este artifício, elaborar a sua própria história. Nesse sentido, o relato de Nael é cheio de dúvidas, no empenho de saber quem é seu pai: a suspeita oscila sobre os gêmeos, ora Yaqub ora Omar.

\section{Em Nur na Escuridão}

Romance de memórias sobre a família do autor. A narrativa conta a saga da família de imigrantes que vem do interior do Líbano e se estabelece inicialmente em Magé, Rio de Janeiro, e depois em Florianópolis, Santa Catarina. O romance inicia com a chegada em 1927 de três libaneses adultos, Yussef, o patriarca; Tamina, a mãe, e Hana, o tio materno, e as três crianças do casal, entre elas, o autor do romance, Salim Miguel.

Na narrativa, montada como um jogo de armar, os temas são variados, comportando idas e vindas no tempo, dúvidas e certezas e um repertório de personagens relacionados à família desses imigrantes e dos patrícios aqui encontrados, ressaltando fatos como a partida do Líbano, a viagem cheia de imprevistos, a chegada no Brasil, as expectativas e frustrações na nova terra, o nascimento dos filhos brasileiros, os rituais de família durante os almoços nos fins de semana até a morte do patriarca Yussef. Os diálogos intercalam o português e o árabe, em assuntos como o mascatear, ou a arte do bom comércio deste imigrante, e os poemas de Omar Kayam.

\section{A FAMÍLIA NA LITERATURA DO IMIGRANTE ÁRABE: UNIÃO DE MEMBROS}

Embora empobrecendo as narrativas, arriscamos essas sinopses para que possamos apresentar ao leitor informações mínimas e proceder a análise antropológica a que nos propomos. Buscando evidenciar os aspectos que representam a família do imigrante árabe no Brasil nessas obras literárias, apoiadas em Geertz, nos seus estudos sobre o islamismo ${ }^{6}$ no Marrocos e na Indonésia, inclinamo-nos sobre as três ficções literárias, esperando "encontrar nelas, no microscópico, o que nos escapa no macro" (1994:20). À primeira vista as três obras apresentam diferenças significativas. No entanto, de outro ponto de vista, incluindo o fato de que todas tratam de famílias de imigrantes libaneses no país, elas permitem uma comparação construtiva. E "por serem ao mesmo tempo muito similares e muito diferentes, contêm reciprocamente algum tipo de comentário uma acerca da outra" (Geertz, 1994:20).

Inicialmente, as famílias síriolibanesas nestas três obras de ficção inclinam-se para um modelo de família nuclear, ou seja, aquela que se compõe dos pais e dos filhos nascidos desta união: em Nur na Escuridão, durante os primeiros anos no Brasil, o tio materno, Hanna, reside com a família da irmã, depois se muda para Porto Alegre; em Lavoura Arcaica é mencionado que o avô (possivelmente paterno) viveu com a família de André até a morte. Contudo, é em Dois Irmãos que este "modelo" está mais distante, pois, além da família composta por Zana e Halime seus filhos, residem na mesma casa Domingas e Nael.

No que tange às relações matrimoniais, o grupo familiar apresenta uma tendência (e não uma regra) claramente endogâmica, ou seja, o imigrante casa "entre os seus", dentre aqueles que fazem parte do seu grupo étnico. É assim sugerido em Lavoura Arcaica com os pais de André; já em Dois Irmãos, Zana e Halim, pais dos gêmeos Yaqub e Omar, casam-se dentro do próprio grupo, apesar das acentuadas diferenças religiosas:

“(...) logo todos na cidade souberam: Halim se embeiçou por Zana. As cristãs-maronitas de Manaus, velhas e moças, não aceitam a idéia de ver Zana casar com um muçulmano.

Encomendaram novenas para ela não se casar. Disseram que ele era mascateiro, um rude, um maometano. Zana, possuída de teimosia, foi falar com o pai. Já havia decidido casar-se com Halim, exigindo deste na frente do pai que teriam de casar-se diante do altar de Nossa Senhora do Líbano, com a presença de maronitas e católicos de Manaus." (2000:53)

A escolha do cônjuge no casal Yussef e Tamina, em Nur na Escuridão, cujo matrimônio foi realizado ainda no Líbano, passa pelo mesmo arranjo matrimonial, ou seja, entre os membros da mesma comunidade árabe. Os personagens casam-se em 1923, antes da vinda para o Brasil, apesar das diferenças de posição social entre ambos:

"[Os parentes] não queriam o casamento por vários motivos: os do lado da mãe, porque não julgavam o pai suficientemente bom para ela, tinham outro candidato, ou nem tinham; os do lado do pai, porque temiam as críticas e tinham (teriam?) alguém para ele." (2000:45)

A endogamia do grupo, que parece fluir nas três obras estudadas, foi, no entanto, quebrada em Dois Irmãos pelos gêmeos: nas duas mulheres de conduta moral duvidosa a que Omar se afeiçoou, as quais foram rechaçadas por Zana, e quando Yaqub casou-se com Lívia, uma não-árabe, e, portanto, brasileira, configurando assim uma situação formal de exogamia, ou seja, casamento "fora do grupo de origem ou pertencimento", tal como se constata na seguinte passagem:

[Diz Zana à vizinha Estelita] "Ela 
mesma, a Livia, filha da tua irmã (...) Pescou meu filho num daqueles cineminhas do teu porão. Yaqub se casou como um cardeal, sem conhecer mulher. Casou escondido, longe da família, que nem um bicho (...)." (2000:249)

Neste sentido, cabe ponderar em que medida o casamento exogâmico contribui para o afrouxamento dos traços que identificam e circunscrevem um dado grupo étnico. No caso de Dois Irmãos, parece-nos que a exogamia praticada pelos gêmeos Yaqub e Omar contribuiu de modo significativo para a dissolução dos laços familiares, os quais já estavam tensionados pela relação tumultuada de ambos, explicitada na disputa por Lívia durante a adolescência. Convém observar que Rânia, a irmã caçula, manteve-se solteira e seu celibato pode ser entendido como um protesto feito à mãe, que rechaçou o único pretendente que de fato a agradou - por outro lado, talvez devido a esta condição Rânia tenha passado à frente dos negócios da família, tomando o lugar do pai no comércio que possuíam. Entretanto, a condição celibatária da mulher árabe - em geral, a filha mais velha - vem a desempenhar um importante papel familiar: o cuidado dos pais na velhice. É isto que ocorre tanto em Dois Irmãos quanto em Nur na Escuridão: no primeiro, Rânia assume os encargos com a mãe viúva; no segundo, Fádua, a mais velha das filhas do patriarca, faz o mesmo quando o pai fica viúvo.

Podemos extrair ainda algumas considerações sobre o incesto nos universos ficcionais de Raduan Nassar e Milton Hatoum, embora ambos tratem do tema diferentemente: em Lavoura Arcaica a situação incestuosa é aberta e em Dois Irmãos é disfarçada. Aliás, neste segundo só poderíamos pensar em incesto se considerarmos o parentesco "fictício" (portanto, social e não biológico) entre Domingas (agregada/ criada da família) e Omar/Yaqub (os gêmeos), pois este não é um incesto entre irmãos consangüíneos, mas entre "irmãos de criação", uma vez que Domingas foi trazida do orfanato ainda menina para ajudar Zana nos cuidados com a casa ${ }^{7}$. Assim como entre Rânia (irmã dos gêmeos) e Nael (filho de Domingas), pois ela pode ser classificada como tia paterna de Nael e por isso, tal como na situação anterior, estes indivíduos estariam impedidos $a$ priori de manter relações sexuais entre si. Assim, o incesto em Dois Irmãos é atenuado e não há punição aos envolvidos. Já em Lavoura Arcaica o incesto entre André e Ana leva a um desfecho trágico: o pai não resiste à desdita da família e comete ato extremo pela quebra do tabu durante a festa que comemorava o retorno de André à família.

Há muito tempo a antropologia vem demonstrando que a proibição do incesto é a possibilidade de constituição de outras famílias e da perpetuação da sociedade humana. Avançando nos passos de Marcel Mauss sobre o caráter da reciprocidade das trocas entre os homens, Lévi-Strauss afirma que a verdadeira razão da proibição universal do incesto é que esta é "uma regra de reciprocidade, porque não renuncio à minha filha ou irmã senão com a condição que meu vizinho renuncie também" (1976:102). Assim, trocam-se mulheres, como se trocam palavras, alimentos, dádivas e contra-dádivas, golpes e pactos. Para o autor, as considerações sexuais não são de importância para o casamento, as medidas econômicas, ou seja, a divisão do trabalho entre os sexos, têm lugar primordial na organização social (1982:369) e é neste sentido é que os laços familiares são mais conseqüência de fatores sociais e culturais do que os de ordem biológica. Sendo assim, prossegue o autor " a proibição do incesto não é mais do que uma espécie de remodelação das condições biológicas do acasalamento e da criação (que não conhecem regras, como se pode observar na vida dos animais), obrigando-os a se perpetuarem estritamente dentro de um esquema artificial de obrigações e de tabus. É aí, e só aí, que encontramos uma passagem da natureza à cultura, da vida animal à vida humana, e que nos encontramos em condições de compreender a verdadeira essência de sua articulação" (1982: 372-3).

Desta forma, na medida em que a família mantém-se "fechada" e não consegue estabelecer alianças com outras famílias (isto é, fornecer um cônjuge, homem ou mulher) ela está fadada ao desaparecimento, ao esfacelamento dos laços familiares e conseqüentemente sociais, pois não consegue efetuar a reciprocidade das trocas tão cara à reprodução da vida social e, no caso de "Lavoura Arcaica" e "Dois Irmãos", do grupo étnico.

Cabe destacar, por outro lado, no tocante às alianças matrimoniais das famílias árabes das narrativas ora em apreço, um dado trazido pelos antropólogos Labourthe-Tolra e Warnier que corrobora o caráter endogâmico destas alianças: a partir das determinações extraídas do Corão que dá "uma parte da herança às mulheres (disposição revolucionária num sistema patrilinear $^{8}$ ), induziu-se no Islam uma forma de casamento preferencial (incestuoso para muita sociedade pagã), que leva os filhos dos irmãos a se casar entre si. Se um filho desposa sua prima paralela $^{9}$, recuperará assim parte correspondente às terras e o patrimônio de seus avós" (1997: 92).

Outro fator que chama a atenção na análise destas obras literárias é o uso intercalado de palavras ou frases em idioma árabe por parte de alguns personagens, e neste sentido convém pensar se isto representaria uma estratégia eficaz de manutenção do idioma árabe entre os imigrantes libaneses. Segundo Salawdeh, não podemos contar com a forma endogâmica de casamento por parte do imigrante árabe, assim como a prática 
da religião islâmica pelo grupo étnico, como fatores que contribuam para a manutenção do idioma árabe entre a comunidade "já que como língua do Islam, o árabe se restringe somente à esfera religiosa e não aos demais setores cotidianos da comunicação e o efeito, no casamento endogâmico, é limitado, devido à ausência de demarcação clara entre o uso do árabe e do português no nível doméstico" (1997:17).

Quanto à alusão ou ao uso do idioma árabe em pequenas frases ou mesmo palavras isoladas no cotidiano familiar das literaturas, verificamos tratar-se de importante instância no processo de construção dos sujeitos nas famílias enfocadas. Tal fato pode ser exemplificado através da narrativa de Nael em Dois Irmãos, ao referir-se à morte de Zana:

“Eu não a vi morrer. Mas alguns dias antes de sua morte, ela deitada na cama de uma clínica, soube que ergueu a cabeça e perguntou em árabe, para que só a filha e a amiga quase centenária a entendessem: 'meus filhos já fizeram as pazes?'” (2000:12)

Em Nur na Escuridão, o uso do idioma árabe é um recurso estilístico que permeia toda a narrativa, tanto nas palavras deste idioma quanto nas dificuldades de aprendizagem da língua portuguesa que o personagem central, Yussef, teve - e aqui cabe salientar quão importante é esta aprendizagem para poder comunicar-se e também trabalhar, uma vez que, nos primeiros tempos de Brasil, a atividade por excelência para qualquer árabe estava relacionada ao comércio, o que não foi diferente para Yussef e seus patrícios: todos mascateavam.

É possível pensar que o contato do grupo de imigrantes libaneses com outros segmentos étnicos no Brasil, ao longo dos anos, tenha enfraquecido, além da língua, a religião. Conforme Pereira, a "esmagadora maioria de imigrantes sírio-libaneses que aportaram no Brasil declarou-se afiliada às igrejas greco-ortodoxa e maronita" (2000:21). Na preferência das novas gerações, essas igrejas foram muitas vezes sendo substituídas pela igreja católica romana. Tal tendência pode ser verificada na passagem em que André, em Lavoura Arcaica, efetua uma busca desesperada pela irmã após o retorno ao lar:

\section{“(...) e foi a toda que me evadi da} casa velha (...) e vi (...) lá onde era a capela, em arco, sua porta estreita aberta, alguém no seu interior acabava de acender as velas (...) Ana estava lá, diante do pequeno oratório, de joelhos, e pude reconhecer a toalha da mesa do altar cobrindo seus cabelos; tinha o terço entre os dedos, corria as primeiras contas, os olhos presos na imagem do alto iluminada entre duas velas." (s/d:186)

A convergência das afiliações religiosas para o cristianismo pelas "famílias árabes", destacada em Dois Irmãos, pode ser apreendida no primeiro encontro entre Domingas e Zana:

\section{"'Uma menina mirrada, que chegou com a cabeça cheia de piolhos $e$ rezas cristãs' (...) lembra Halim. (...) 'Zana gostou dela. As duas rezavam juntas as orações que uma aprendeu em Biblos, no Líbano, e a outra no orfanato das freiras, aqui em Manaus. O que a religião é capaz de fazer', ele disse. 'Pode aproximar os opostos, o céu e a terra, a empregada e a patroa."' (2000:65)}

Entretanto, o maktub (= "está escrito") islâmico, as histórias orientais também estão presentes junto às parábolas do cristianismo repetidas à mesa dos sermões dados pelo patriarca da família em Lavoura Arcaica. Isso pode ser constatado na abertura do segundo capítulo, intitulado " $O$ Retorno", cuja epígrafe retirada do Corão, livro sagrado do islamismo, é um versículo que indica um interdito e nos diz coisas centrais do enredo da obra:

"Vos são interditadas: vossas mães, vossas filhas, vossas sobrinhas, vossas nutrizes, vossas amas de leite." (Surata "As Mulheres" - IV, 23) (s/d:213)

No que se refere às transmissões dos ensinamentos de parábolas milenares do povo árabe no cotidiano familiar de Nur na Escuridão, o narrador, ao recordarse do pai, o velho Yussef, capítulo "Orgulho" confirma o fato no momento em que este não cansava de explicar:

"As fábulas anônimas, tão vivas, de tanta sabedoria, resultado de um imaginário fértil, que me devolve intacto o orgulho de ser árabe, de qual época, parte, seita, religião." (2000:164)

\section{CONSIDERAÇÕES FINAIS}

Nos limites deste artigo e na tentativa de síntese, podemos dizer que a reflexão aqui empreendida das categorias de família e parentesco do imigrante árabe nas obras de escritores que também possuem esta ascendência não pretendeu de forma alguma esgotar as possibilidades de análise que essas obras apresentam. Nossa intenção foi (e é) suscitarl a discussão sobre a temática da migração árabe na sociedade brasileira mediante uma referência empírica a nosso ver pouco investigada, que é a literatura de ficção. Nesse sentido, parece-nos que tomar a literatura como etnografia pode se constituir num campo muito profícuo para se pensar comparativamente estas mesmas temáticas em relação a imigrantes de outras nacionalidades, o que sem dúvida contribuiria para análises antropológicas mais amplas.

* Janie K. Pacheco e Lenora S. Pereira são Mestres em Antropologia Social pelo PPGAS da Universidade Federal do Rio Grande do Sul. 


\section{NOTAS}

1 - Segundo Lewis (1982), o termo "árabe" era originalmente uma categoria lingüística, designando aquele que falava a língua árabe, em especial os beduínos, reputados como falantes de um árabe mais puro e, assim, identificados como nômades em oposição aos habitantes das cidades. Após a conquista turca no século XVI da Síria, Mesopotâmia, Costa Arábica, Egito, norte da África e Hungria, a expressão passou a designar a população árabe em oposição aos turcos. Posteriormente, com a criação dos Estados Nacionais no conjunto das sociedades muçulmanas que reivindicavam o patriotismo local ou étnico (turco, argelino, sírio, egípcio, etc.), a palavra "árabe" se tornou uma categoria que designa aqueles que falam a língua árabe e compartilham da cultura árabe e a experiência histórica que a acompanha.

2 - Atualmente o fenômeno das minorias culturais e religiosas mantém estreita relação com as características da época em que vivem e não é uma questão regional ou nacional, quando se avalia o expressivo número de pessoas que vivem fora de sua nação. Para Zéghidour, atualmente são cerca de cem milhões os indivíduos nesta situação, entre os quais 16 milhões de árabes (1982:90).

3 - Segundo Barth, "grupos étnicos são (...) uma forma de organização social. Então um traço fundamental [é] a característica de atribuição e auto-atribuição por outros a uma categoria étnica. (...) $\mathrm{Na}$ medida em que os atores utilizam identidades étnicas para categorizar a si mesmos e aos outros, com objetivos de interação, eles formam grupos étnicos neste sentido organizacional" (1998:193-4).

4 - Neste sentido, a partir do ensaio de Viveiros de Castros \& Benzaquen de Araújo sobre a história de Romeu e Julieta, é correto afirmar que o amor como motivador do casamento (ou da união por livre escolha) dos parceiros só existe quando o "indivíduo está liberto dos laços sociais, não mais derivando sua realidade dos grupos a que pertença, mas em relação direta com um cosmos composto de indivíduos, onde as relações sociais valorizadas são as interindividuais. $O$ amor (...) [passa então a ser] visto como uma relação entre indivíduos, no sentido de seres despidos de qualquer referência ao mundo social, e mesmo contra este mundo"(1977:131).

5 - Esta relação pode ser remetida à análise dos mitos envolvendo gêmeos elaborada por Lévi-Strauss (s/d). Segundo o autor, é crença em muitas sociedades tradicionais que os "gêmeos ou até mais crianças no ventre da mãe (...) começam a lutar e a competir para decidir quem terá a honra de nascer em primeiro lugar" (s/d: 49). No romance de Hatoum esta situação seria confirmada pelo adoecimento de Omar, o segundo dos gêmeos a nascer, logo nos primeiros meses de vida, dando início ao excessivo zelo materno.

6 - De acordo com Nabhan (1996:11), em árabe, tanto o termo islamismo, ISLAM, quanto muçulmano, MUSLIM, derivam do radical consonantal SLM, que significa "aquele que se rende", aquele que se submete à vontade de Deus. "Islamismo" é uma categoria que indica adesão a um determinado sistema religioso, havendo muçulmanos árabes, turcos, curdos, persas, indonésios, japoneses etc.

7 - Tomamos aqui a idéia de "circulação de crianças" formulada por Fonseca para pensar a colocação de Domingas na casa de Zana e Halim, uma vez que ela foi para esta casa "em idade de ser útil nos afazeres domésticos" e acabou por ser criada das outras crianças da casa (Fonseca, 1995:79).

8 - Segundo Laburthe-Tolra \& Warnier, na filiação patrilinear, "todo indivíduo é membro do grupo parental consangüíneo de seu pai" (1997:108). Na filiação matrilinear dá-se o contrário.

9 - "Os primos cujo parentesco se origina de dois irmãos ou de duas irmãs são primos paralelos, enquanto que aqueles cujo parentesco provém de sexos opostos são primos cruzados" (Lévi-Strauss, 1982:375).

\section{REFERÊNCIAS BIBLIOGRÁFICAS}

BARTH, F.

(1998) "Grupos étnicos e suas fronteiras". In: POUTIGNAT, P. \& STREIFF-FENART, J. Teorias da etnicidade. São Paulo, Unesp.

DAMATTA, $R$.

(1993) "A obra literária como etnografia: notas sobre as relações entre literatura e antropologia". In: Conta de Mentirososete ensaios de antropologia brasileira. Rio de Janeiro, Rocco.

FONSECA. C.

(1995) "Somando mães". Caminhos da adoção. São Paulo, Cortez.

GEERTZ, C.

(1994) Observando el Islam. Barcelona, Paidós.

HATOUM, $M$.

(2000) Dois irmãos. São Paulo, Cia das Letras.

JARDIM, D. (2001)

Palestinos no Extremo Sul do Brasil. Rio de Janeiro, UFRJ/Museu Nacional (Tese de Doutorado)

LABURTHE-TOLRA, P. \& WARNIER, J.P. (1997) Etnologia - Antropologia. Petrópolis, Vozes.

LÉVI-STRAUSS, C.

(s/d) Mito e significado. Lisboa, Edições 70.

LÉVI-STRAUSS, C.

(1976) "O princípio da reciprocidade". In: Estruturas elementares do parentesco. Petrópolis, Vozes.

LÉVI-STRAUSS, $\mathrm{C}$.

(1982) "A família". In: SHAPIRO, H. (org.) Homem, cultura e sociedade. São Paulo, Martins Fontes.

LEWIS, B.

(1982) Os árabes na história. Lisboa, Estampa.

MIGUEL, S.

(2000) Nur na escuridão. Rio de Janeiro, Topbooks.

NABHAN, N. N.

(1996) O islamismo de Maomé a nossos dias. São Paulo, Ática.

NASSAR, R.

(s/d) Lavoura arcaica. São Paulo, Círculo do Livro.

PEREIRA, J.B.B.

(2000) "Os imigrantes na construção histórica da pluralidade étnica brasileira". Revista USP, n46, 2000.

PEREIRA, L. $S$.

(2001) A discreta presença dos muçulmanos em Porto Alegre. Porto Alegre, PPGAS/UFRGS (Dissertação de Mestrado).

SALAWDEH, O. K.

(1997) Manutenção e mudança da língua árabe - um estudo na comunidade árabe em São Paulo. Campinas, Unicamp (Dissertação de Mestrado).

SAFADY, J.

(1994) A imigração árabe no Brasil. São Paulo, Garatuja

SAMIR, $\mathrm{H}$.

(1994) Os significados dos versículos do Alcorão Sagrado. São Bernardo/SP, Mar Sam.

TRUZZI, O.

(2000) "Patrícios, dinheiro, diploma e voto: a saga da imigração árabe".

Revista Veja, (04/10)

VIVEIROS DE CASTRO, E. \& BENZAQUEN

DE ARAÚJO, R.

(1977) "Romeu e Julieta e a origem do Estado" In: VELHO, G. (org.) Arte e sociedade - ensaios de sociologia da arte. Rio de Janeiro, Zahar.

ZÉGHIDOUR, S.

(1982) A poesia árabe no Brasil. São Paulo, Brasiliense. 